\title{
Chapter 2 \\ The Conceptual and Empirical Challenges of Estimating Trends in Union Stability: Have Unions Become More Stable in Britain?
}

\author{
Diederik Boertien
}

\begin{abstract}
This chapter provides an overview of the conceptual and empirical challenges that arise once measuring union stability. Conceptually, the chapter discusses different ways of defining unions and what each way implies in terms of measurement. For the purposes of this chapter, union stability is defined as the stability of both marriages and co-residential unions. Available data sources are discussed as well as their possible biases. Empirically, the chapter compares two data sources from Britain to show that there are serious challenges to be overcome when using survey data to estimate trends in union stability. Survey data possibly overestimates union stability due to selective non-response and prospective surveys do not report many unions that existed according to retrospective data. Good news comes from a comparison of two retrospective sources which provide relatively consistent estimates of trends in union stability. If retrospective information is indeed to be trusted, union stability has been decreasing across cohorts (1974-1999), but this development appears to have stalled for the most recent cohort formed in 2000-2004. A lack of recent data, however, prevents us from knowing whether this trend has continued, underlining the need to invest in the repeated collection of retrospective union histories.
\end{abstract}

Keywords Union dissolution · Cohabitation · Separation · Data quality $\cdot$ Attrition

\footnotetext{
D. Boertien $(\varangle)$

Centre d'Estudis Demogràfics, Bellaterra, Spain

e-mail: dboertien@ced.uab.es 


\subsection{Introduction}

The dramatic increases in divorce rates in Western societies over the last decades have provided a fertile ground for theories regarding individual and couple behavior (Wagner et al. 2015). The increased prevalence of divorce has been regarded as an indication of a greater value put on personal autonomy (Lesthaeghe 1995) and changing expectations of relationships (Cherlin 2004). It has also been regarded as reflecting changes in relationship dynamics between men and women, with women having increasingly more control over their own lives and couple behavior (Becker et al. 1977; Oppenheimer 1997). Recently, scholars have started to pay attention to a break in the trend of increasing divorce rates. Since the 1980s, divorce rates have arrived at a plateau and recently possibly started to decline again in the United States (Cohen 2018; Kennedy and Ruggles 2014; Stevenson and Wolfers 2011; U.S. Census Bureau 2007). Crude divorce rates have also been dropping in some European countries (Esping-Andersen 2016).

If increases in divorce rates have been consequential for our thinking about couple life, a partial reversal of that trend should provoke new theories and explanations too. But the recent possible stabilization of marriage has not yet sparked great interest from scholars. This could well be because the selection of people into marriage has changed over time. Not all cohabiting relationships are formalized through marriage anymore, and many children grow up in households where parents are not married (Heuveline and Timberlake 2004). Divorce rates therefore decreasingly cover all of couple and family life, and the usefulness of the indicator has consequently changed over time (Cherlin 2010). A logical question would therefore be to ask: Has the stability of unions in general changed over time?

The aim of this chapter is to try and answer this question for cohabiting unions and marriages in Britain. Unfortunately, switching from the study of marital stability to the study of union stability is fraught with conceptual and empirical challenges. An important goal of this book chapter is to give an overview of these different challenges, and to provide recommendations for future data collection and research. Problems in the estimation of levels of cohabitation and divorce have been getting attention over the last decades (Manning and Smock 2005; Hayford and Morgan 2008; Kennedy and Ruggles 2014), but barely any attention has been paid to the estimation of trends in union stability.

The chapter will be organized according to two main sub-questions. Firstly, how to define unions and should all types of relationships be included in estimates of union stability? In this section, rather than providing an account of what a union exactly is, different practical options are reviewed in terms of how well they allow for unequivocal measurement and how likely they are to be relevant for social science research. Secondly, what data is the most appropriate to empirically document trends in union stability? To answer the second question I will discuss various possible sources available (e.g. administrative data, longitudinal surveys, and retrospective union histories) and the possible biases introduced by using each source of data. To get insight into how serious these biases are, several tests will be performed 
in the empirical section of the paper using the British Household Panel Survey and Understanding Society data. Based on the results of these tests, an as best as possible estimate of changes over time in union stability in Britain will be provided.

\subsection{The Conceptual Switch from Marital to Union Stability}

Ever more relationships in Europe diverge from the 'traditional' route of a period of courtship followed by marriage and children. Widely used indicators such as marital stability therefore no longer cover the great majority of relationships and families in society (Cherlin 2010). Is it possible to create a new measure of union stability that has the same qualities that measures of marital stability once had: straightforward measurement and covering most long-term relationships in society?

Legal marriages have a clear starting date and include a ceremony that, at the least, includes a declaration of being a couple in legal terms. Legal agreements can be collected by authorities to compile official statistics on marriage. Other relationship forms often do not have such a clear moment where the relationship status of a couple is declared. For instance, it is not uncommon that the question when a couple started 'dating' leads to a conversation between partners aimed at re-constructing past events. Such a question can be interpreted in various ways (e.g. first romantic involvement, informal declaration of being a couple). If one cannot clearly measure when a relationship starts, how do we know who is in a relationship at a given point in time?

A moment of transition might be clearer in the case of cohabiting unions. Many cohabiting couples sign cohabitation agreements or register in other ways with authorities (Perelli-Harris and Gassen 2012). Registered partnerships therefore should be identifiable in a manner similar to marriages. However, many cohabiting partnerships are never registered with authorities. A new measure of union stability that only includes registered partnerships and marriages is therefore still likely to leave many long-term relationships out of consideration. Are there other relatively objective ways of defining the start of a cohabiting relationship?

One might consider the moment a couple moves in together as the start of a coresidential relationship. However, qualitative research has shown that people often gradually move in with each other, starting with staying over a couple of nights a week and ending in full-time co-residence (Manning and Smock 2005). Such sliding into cohabitation makes it hard to pin down the start of a co-residing relationship. There might be relatively objective ways of determining co-residence of two persons such as the registration at a certain address or, for instance, counting the number of nights one spends outside of the partner's home (excluding travels). There are some limitations to determining co-residence in such ways, including possible failures to register a new address. But more importantly, the co-residence of two persons does not necessarily imply that they are a couple. One might therefore define co-residence in such a way that it should be measurable in a relatively objective way, but in order to measure co-residential romantic unions it will always be necessary to ask co-residing individuals whether they are a couple or not. 
A new measure of union stability that includes cohabiting unions will therefore necessarily have to rely on some form of self-reported relationship status, an essential difference as compared to measures of marital stability. But, if the definition of a union ultimately depends on the self-identification of couples as such, why should we categorically exclude other relationships that also depend on such selfidentification? For instance, definitions of non-residential relationships rely on individuals perceiving themselves as being a couple (Strohm et al. 2009:177). Such non-residential relationships can include 'Living Apart Together' (LAT) relationships which sometimes are defined as having an explicitly expressed long-term commitment between partners (Connidis et al. 2017:1407), but also other 'dating' relationships that consist of non-residential relationships that do not necessarily include a long-term commitment.

If self-identification cannot be avoided in the measurement of union stability, what would be objections against including all self-declared relationship in the construction of such a measure? Marital stability has been such a widely studied topic, not only because marriage was the major ambit within which relationships took place, but also because marriage impacts well-being (Amato 2010), is an arrangement within which economic resources can be pooled (Lyngstad et al. 2010), affects social networks (Kalmijn 2012a) and relationships between family members when dissolved (Kalmijn 2012b), and marriage used to be the primary setting within which children were born and raised (Perelli-Harris et al. 2012). Furthermore, marriages involve a division of paid and unpaid labor and are therefore defining for gender relations (Brines 1994). Due to these characteristics of marriage, changes in divorce rates have been of concern for theories and research on topics such as gender relations (Esping-Andersen and Billari 2015; Goldscheider et al. 2015; Oppenheimer 1997), child development (Amato 2010; Härkönen et al. 2017), and inequality of opportunity (McLanahan and Percheski 2008).

In other words, marriage and divorce have an impact on people's lives. The selfdeclaration of being in a couple with another person by itself does not imply any kind of impact on people's lives. Marriage, at the minimum, requires an agreement on the legal responsibilities partners decide to have toward each other, and therefore by definition has some impact on people's lives. Even though most relationships affect mental well-being, gender relationships, and economic standing, there might be many self-declared relationships that have relatively little impact on people's lives. In other words, a change in the stability of self-declared relationships is not likely to be as consequential for people's lives as a change in marital stability. The inclusion of all self-declared relationships in indicators of union stability, regardless of their impact on people's lives, might therefore reduce its usefulness for many of the research questions asked in social science research.

One solution would be to look at long-term commitment between partners, as has been done to distinguish certain types of LAT relationships (Connidis et al. 2017:1407). A long-term commitment requires coordination of behavior between partners. Committed relationships are therefore likely to have more impact on 
people's lives as compared to less committed relationships. Are there relatively objective ways to measure commitment? One way might be to focus on common investments made by the couple, with as the clearest example having children together (Aarskaug Wiik et al. 2009). However, not all couples with a long-term commitment have children, including those who want but do not have children, and not all fertility is intended. Nonetheless, looking at the stability of families with children has been an approach taken by recent studies (Brown et al. 2016; Musick and Michelmore 2018; Thomson and Eriksson 2013) and is especially relevant for questions on child development and inequality of opportunity (McLanahan and Percheski 2008). Another objective indicator could be the joint ownership of assets such as a home. However, a measure based on the ownership of economic resources is likely to only cover (economically) select parts of society.

If commitment is hard to measure objectively using a single measure applicable to all relationships, a solution might be to consider co-residence as an indicator of how impacting a relationship is on people's lives. In this case, the definition of coresidence is crucial, but if (a minimum period of) co-residence involves sharing bills, rent, and determining the division of domestic labour, it has at least some impact on people's lives. Similar to marriage, where the declaration of being a legal couple requires a minimum coordination of legal responsibilities, co-residence also requires a minimum level of coordination of economic and practical responsibilities. This is a defining feature that non-resident self-declared relationships do not necessarily have.

Summing up, there seem to be three general options available regarding the type of relationships that can be included in the construction of a new measure of union stability: (1) include registered partnerships and marriages; (2) include self-declared co-residing couples and marriages; (3) include all self-declared couples and marriages. Option 1 can be measured in a way that does not require the self-identification of couples. However, Options 2 and 3 are likely to cover more of the total universe of relationships that have an impact on people's lives. Given that Option 3 runs the risk of also including relationships that do not have a major impact on people's lives, I give preference to Option 2 in this chapter.

There are several objections that can be made against this choice. For instance, one might argue that committed LAT-relationships impact people's lives as much as many co-residential unions. However, until conceptual developments are available allowing for a relatively objective identification of commitment in relationships, it does not seem straightforward to distinguish committed LAT-relationships from other non-residential relationships. One might also argue that co-resident relationships comprise a large variety of relationship forms that range from marriage-like unions to relationships that resemble 'dating' without any clear commitment (Heuveline and Timberlake 2004; Hiekel et al. 2014; Kiernan 2004). One could therefore not consider all cohabiting unions as equally relevant for a measure of union stability. A counterargument could be that marriages might also have low commitment and can dissolve as soon as bumps on the road appear. But this is a debate that is likely to remain open. 


\subsection{Estimating Trends in Union Stability}

If the goal is to estimate the duration of co-resident relationships and marriages, what measures and data are available to do so? In general, three types of sources have been used: administrative data, prospective and retrospective survey data. Each of these sources is discussed in turn.

\subsubsection{Administrative Data}

Governmental bodies often have information on co-residence of individuals, but such administrative data do often not record whether co-resident individuals are a couple, unless they legally registered their partnership. Administrative data has been used in studies on both cohabitation and separation, but such data either requires restricting the sample to parents of common children (Thomson and Eriksson 2013) or requires additional assumptions such as the assumption that adults of the oppositesex who live together are a couple (Jalovaara and Kulu 2018). Another avenue is to perform consistency checks based on other characteristics available in the data, or to calculate the likelihood that two co-resident individuals are a couple (Esteve et al. 2012). It remains unclear, however, how often such assumptions and procedures lead to miscoding single individuals as couples, and how consequential this is for estimates of trends in unions stability based on administrative data.

Jalovaara and Kulu (2018) used Finnish registry data which has the unique feature of identifying residence at the dwelling level. They considered two co-residing individuals to be a couple if they co-resided in the same dwelling for 90 days or more, were not close relatives, had the opposite-sex and did not have an age difference of more than 20 years. Such a definition likely includes most cohabiting relationships, but might also include individuals of the opposite-sex who are co-residing but not romantically involved. They report that in the Finnish European Social Survey rounds 2002-2014, $0.6 \%$ of respondents reported to be co-residing with an unrelated adult of the opposite-sex without being a couple (Jalovaara and Kulu 2018: Supplementary Material). More research is needed to investigate how consequential such a prevalence of miscoding is for the estimation of trends in union stability. At the same time, administrative data offer qualities as compared to survey data (see next sections). Finally, administrative data is currently only available to researchers in a limited set of countries.

\subsubsection{Survey Data}

Survey data has been used in several existing studies on union stability (Brown et al. 2016; Raley and Wildsmith 2004). Survey data allow for the inclusion of selfreported couple status, but can be biased due to either misreporting or due to selective non-response (Mitchell 2010). 
Most existing findings on misreporting that are relevant for this chapter come from studies on the measurement of cohabitation. Determining whether a couple is cohabiting is not always straightforward for survey respondents (Manning and Smock 2005). The terminology used to determine couple status appears important in this regard. Manning and Smock (2005) found in their qualitative study that many individuals find the term "unmarried partner" confusing, which is often used in large US datasets. Besides not being sure whether one fits a certain definition, some couples might be hesitant to disclose their union status out of fear of losing welfare benefits or due to social stigma (Murphy 2000; Teitler et al. 2006). In line with these arguments, prospective data indeed showed lower rates of cohabitation as compared to retrospective data in various studies (Berrington et al. 2011; Murphy 2000; Teitler et al. 2006).

However, differences with prospective data might also emerge because retrospective data over-reports cohabitation. Teitler et al. (2006) indicate two possible ways people might misreport events in case they do not re-call them accurately. Firstly, people tend to aim for consistency in the states they report, which leads to the tendency to apply a current situation to the situation reported on in the past. Secondly, memories are affected by current emotions, which could lead respondents to retrospectively "downgrade" the status of past unions. More concretely, if union status in the past was ambiguous, respondents might decide that the union 'existed' if it exists today, and might decide that it did not 'exist' if the relationship dissolved. They found support for these expectations by comparing retrospective and prospective reports on cohabitation from the Fragile Families Study.

The Fragile Families Study asked mothers after giving birth whether they cohabited with the father of their child. One year later, mothers were asked retrospectively whether they cohabited with the father of their child at the time of birth. Respondents in general "upgraded" their reports of union status at birth, with many women not reporting being in a cohabiting relationship at birth, but reporting that they did in retrospective reports. However, women whose relationship with the father had dissolved by the second round of interviews often "downgraded" their relationship: they had an increased probability of retrospectively reporting not having cohabited with the father at birth, even though they indicated they did prospectively (Teitler et al. 2006). If retrospective reports on relationship status indeed depend to an important extent on current relationship status, this might lead to an overestimation of union stability: unions that survive are reported whereas unions that do not survive are omitted.

There are additional reasons to expect union stability to be overestimated in retrospective union histories. Re-call bias might lead people to omit reports on (short) cohabiting unions that took place in the distant past. Hayford and Morgan (2008:129) found that "cohabitation histories underestimate cohabitation rates in distant periods relative to rates estimated closer to the date of survey". Teitler et al. (2006) found larger discrepancies between prospective and retrospective reports of cohabitation if both measurement points were spaced apart further in time.

Besides misreporting, another source of bias in survey data is non-response (Mitchell 2010). Selective non-response can arise when individuals with unstable 
union trajectories are less (or more) likely to respond to a survey, or because they are more likely to drop out of longitudinal surveys. All estimates from survey data have to deal with differential response rates but selective attrition would form a major obstacle to the use of longitudinal prospective data in particular. Several studies have shown how attrition is related to marital status (Mitchell 2010; Young et al. 2006). If attrition is based on characteristics observed in previous waves, such attrition might be adjusted for by using sample weights. On the other hand, if attrition is directly related to the event of union dissolution, such adjustments are not likely to be of help. Individuals who separate between waves of a longitudinal survey might be especially likely to drop out of a survey because of two reasons: a) union dissolution includes residential mobility for at least one individual, which might complicate contacting survey respondents in a follow-up round; b) It can be expected that individuals who recently separated are not very eager to cooperate with a survey (Young et al. 2006), especially if this includes questions on their relationship history. To what extent events of separation are related to attrition is still to be investigated.

\subsubsection{This Study}

Most of the existing empirical evidence on the sources of bias discussed so far comes from studies on the levels of cohabitation. In this chapter, the goal is to use data from Britain to test whether these issues also lead to biased estimates of trends in union stability.

Firstly, data from the British Household Panel Survey (BHPS) is employed. The BHPS collected both prospective and retrospective data on union histories, and these overlap for one year (1991-1992). This allows us to test for a consistent sample of respondents whether reports of union stability differ between prospective and retrospective sources. There are several possible expectations in this regard:

Hypothesis 1a: If retrospective reports of union status are influenced by current union status, retrospective reports overestimate union stability.

Hypothesis $1 b$ : If prospective data under-report cohabitation unions, either due to ambiguity of a couple's union status or due to purposeful misreporting, prospective reports overestimate union stability.

Secondly, the household design of the BHPS allows us to follow both partners after union dissolution. This enables comparing general patterns of attrition to attrition among one of the two separated partners. In this regard it is expected that:

Hypothesis 2: The event of separation is related to higher levels of attrition.

Finally, I test the possible influence of re-call bias by comparing the retrospective data from the BHPS collected in 1992 to retrospective data from a comparable survey: Understanding Society. Retrospective union histories were collected in 2009/2010, the first wave of the survey. The combination of these datasets allows us 
to check for consistencies in reports on union stability for the period 1975-1991 in Britain. The expectation is that:

Hypothesis 3: If separation events in the distant past are less likely to be reported, retrospective union histories that are collected further away in time are likely to overestimate union stability.

Finally, I aim to document the overall possible consequences of these biases by testing to what extent different data sources produce different estimates of trends in union stability. I compare the family histories of the BHPS (Pronzato 2011) to retrospective reports from the first wave of Understanding Society collected in 2009/2010. The BHPS family histories are based on a combination of retrospective data collected in 1992 with prospective longitudinal data covering 1991-2008. Comparing this data to retrospective reports from 2009 allows us to compare estimates of union stability from a retrospective source to estimates from prospective data.

\subsection{Data and Method}

This study employs information from retrospective union histories recorded by the BHPS and Understanding Society studies (University of Essex 2010, 2018). Both are longitudinal surveys representative to the British population and apply similar definitions of unions and their dissolution. The retrospective union history module of the BHPS collects respondents' information for up to four marriages (collected in 1992). It starts by asking what month and year each marriage took place, followed by a question whether the respondent and partner did "live together as a couple before getting married" and if so what month and year they started living together. Dissolution is measured by asking the month and year when the couple stopped living together and the reason the union ended (e.g. separation, divorce or death). After collecting information on marriage, a cohabitation section starts where respondents are asked if they "ever lived with someone as a couple for three months or more", and if so, how many partners they lived with for more than 3 months outside of marriage. For each of these partners respondents are asked which month they started and stopped living together.

The union history module of Understanding Society imported the structure and questions from the BHPS, but with some slight modifications. Most importantly, the module starts with asking details on the current marriage, and subsequently on all previous marriages (rather than starting with the first and recording up to four marriages). Hannemann and Kulu (2015) found a high degree of consistency between estimates of levels of marriage and divorce once comparing Understanding Society data to official statistics.

Part of the analysis relies on prospective information on unions from the BHPS. This data is derived from information on yearly questions whether and with whom persons were "married" or "living as a couple", combined with yearly questions on whether, when and why (e.g. divorce/separation/deceased/left for job, etc.) persons present in the household in the previous interview left the household and 
vice versa (i.e. whether new persons entered the household as compared to last year). The prospective data might therefore miss short cohabitation spells that took place between waves. In this chapter, once comparing prospective to retrospective sources, short cohabitation spells (of less than a year) are excluded from the sample when relevant.

Several samples are employed in this study. Firstly, prospective and retrospective reports on union histories are compared for respondents interviewed both in the 1991 and 1992 waves of the BHPS. This sample excludes respondents who joined or dropped out of the survey in 1992. All respondents who reported either retrospectively or prospectively to have been in a cohabiting union or marriage at the time of interview in Wave 1 were included $(\mathrm{N}=6033)$.

Secondly, to compare estimates of trends in union stability across union cohorts between the BHPS and Understanding Society data, I restrict the sample to first unions formed between 1975 and 2004. The restriction to first unions is motivated by the slight difference in the total number of marriages recorded in the BHPS. Women's information on unions is used given that they consistently appear to provide more accurate information on family events than men (Mitchell 2010). The only further requirement for inclusion was the presence of a starting date and an ending date if the union dissolved before last interview. Unions were right-censored if a partner passed away, or if the couple was still intact at the date of last interview. Transitions from cohabiting to married unions were not regarded as a union end.

Besides differences in survey instruments, there might be differences in the sample composition across data sources. To compare the BHPS to Understanding Society, I limit the BHPS sample to those present in 2008 and employ sample weights provided that account for attrition and the inclusion of temporary sample members. The first wave of Understanding Society is included and sample weights for the year 2009 are used. To take further possible differences in sample composition into account, controls are included for several characteristics including country (England, Northern Ireland, Scotland, Wales), ethnicity (Asian, Black, Other, White), being foreign born and education (ISCED 1-2; ISCED 3-4; ISCED 5-6). When comparing retrospective union histories recorded in 1992 in the BHPS to retrospective histories collected in 2009 by Understanding Society, respondents from Northern Ireland and individuals who arrived to Britain after 1991 were excluded from the Understanding Society data, again to make the sample comparable to the BHPS in 1992.

\subsection{Results}

\subsubsection{Comparing Retrospective and Prospective Reports Using a Consistent Sample}

The results section starts by testing various hypotheses about sources of bias in the estimation of union stability. Table 2.1 compares retrospective and prospective reports on the dissolution of unions between Waves 1 and 2 of the BHPS. The infor- 
mation comes from 6033 respondents who reported being in a union at the time of interview in Wave 1 either prospectively (In Wave 1) or retrospectively (In Wave 2). $94.3 \%$ of respondents provided consistent information on union stability. $2.7 \%$ of cases had information on couple status in Waves 1 and 2, but did not complete the retrospective history module. A remaining 3.1\% provided inconsistent information. Even though this might seem as a small percentage, out of the 223 reports of a separation recorded across both sources only $58 \%$ were reported both prospectively and retrospectively. Does this discrepancy lead to biased estimates of union stability?

Some mismatches across sources are likely to arise because of small retrospective misreports of the month at which unions were formed or dissolved. If one assumes such measurement error to be random, we would expect retrospective and prospective reports, on average, to produce consistent estimates of union stability. However, based on retrospective data $3.4 \%$ of unions dissolved between waves, whereas prospective data would lead to a dissolution estimate of $2.8 \%$.

This pattern of lower stability in retrospective reports was predicted if prospective reports do not capture all cohabiting unions in vigor due to unclear definitions or deliberate misreporting. It goes against the expectation that current union status dictates reports on past union statuses and therewith biases estimates of stability upward. Further support for this conclusion is provided by the more detailed numbers of Table 2.1. The most common inconsistency across sources consists of respondents who retrospectively reported a separation between interviews, but did not prospectively indicate being in a union in Wave 1 (53\% of all separations not consistently recorded). An additional inspection of the actual union formation and dissolution months reported in the retrospective data confirmed that the great majority of these cases are unlikely to be due to the misreporting of specific months (not shown). Even though 50\% of these 'missing separations' consisted of unions that started in the 4 years before Wave 1, only 6 cases started 4 months or less before

Table 2.1 Comparison of retrospective and prospective info on separations between waves 1 and 2 of the BHPS

\begin{tabular}{|c|c|c|c|c|c|c|}
\hline & \multicolumn{4}{|c|}{ Retrospective data } & \multirow[b]{2}{*}{ Total } \\
\hline & & $\begin{array}{l}\text { Separation } \\
\text { between } \\
\text { Waves }\end{array}$ & $\begin{array}{l}\text { No union } \\
\text { in wave } 1\end{array}$ & $\begin{array}{l}\text { Union in wave } \\
1 ; \text { no } \\
\text { separation }\end{array}$ & $\begin{array}{l}\text { No } \\
\text { retrospective } \\
\text { info }\end{array}$ & \\
\hline \multirow[t]{5}{*}{$\begin{array}{l}\text { Prospective } \\
\text { data }\end{array}$} & $\begin{array}{l}\text { Separation } \\
\text { between waves }\end{array}$ & $133(2.2 \%)$ & $\begin{array}{l}23 \\
(0.4 \%)\end{array}$ & $6(0.1 \%)$ & $2(0.0 \%)$ & 164 \\
\hline & $\begin{array}{l}\text { No union in } \\
\text { wave } 1\end{array}$ & $51(0.8 \%)$ & N/A & $58(1.0 \%)$ & N/A & 109 \\
\hline & $\begin{array}{l}\text { Union in wave } \\
1 ; \text { no } \\
\text { separation }\end{array}$ & $14(0.2 \%)$ & $\begin{array}{l}27 \\
(0.4 \%)\end{array}$ & $5550(92.0 \%)$ & $164(2.7 \%)$ & 5755 \\
\hline & $\begin{array}{l}\text { No info in } \\
\text { wave } 1\end{array}$ & & N/A & $5(0.1 \%)$ & N/A & 5 \\
\hline & Total & 198 & 50 & 5619 & 166 & 6033 \\
\hline
\end{tabular}

Note. Only includes information on individuals that indicated being in a union at Wave 1 either in prospective or retrospective data. Separations are defined in both sources as ceasing to live together 
Wave 1 . In addition, even though slightly more of these retrospectively reported separations took place in the months after interview, they are relatively evenly distributed across months between waves (e.g. $50 \%$ reported the separation to have taken place 6 months or later after the Wave 1 interview).

\subsubsection{Re-call Bias}

The comparison of reports from prospective and retrospective sources suggests that prospective data might overestimate union stability. Retrospective union histories might be affected by re-call bias, which would be more serious for events further in the past. Do retrospective histories spaced apart 17 years in time produce different estimates of union stability?

Table 2.2 compares trends in union stability for the period 1976-1992 based on retrospective data from the BHPS (1992) and Understanding Society (2009). The time period and samples of both surveys were harmonized for this table. Most importantly, the BHPS sample consists of respondents present in 2008 to account for possible selective mortality between 1992 and 2008 (sample weights are included). Models 1 and 2 show how both sources produce relatively consistent

Table 2.2 Proportional hazard models of union dissolution by data source; 1976-1992

\begin{tabular}{|c|c|c|c|c|c|c|c|c|c|c|}
\hline & \multicolumn{2}{|l|}{ BHPS } & \multicolumn{2}{|c|}{ Unders. society } & \multicolumn{6}{|c|}{ Pooled data } \\
\hline & Haz.R & SE & Haz.R & SE & Haz.R & SE & Haz.R & SE & Haz.R & SE \\
\hline & \multicolumn{2}{|l|}{ Model 1} & \multicolumn{2}{|l|}{ Model 2} & \multicolumn{2}{|l|}{ Model 3} & \multicolumn{2}{|l|}{ Model 4} & \multicolumn{2}{|l|}{ Model 5} \\
\hline \multicolumn{11}{|c|}{ Union cohort (Ref. 1975-79) } \\
\hline $1980-1984$ & 1.00 & 0.24 & $1.30 * *$ & 0.10 & $1.23 * *$ & 0.10 & . & . & . & . \\
\hline 1985-1989 & $1.69 * *$ & 0.40 & $1.77 * *$ & 0.16 & $1.80 * *$ & 0.16 & . & . & . & . \\
\hline 1990-1991 & $2.86 * *$ & 1.26 & $2.13 * *$ & 0.38 & $2.26 * *$ & 0.39 & . & . & . & . \\
\hline \multicolumn{11}{|c|}{ Dataset (Ref. Un. Society) } \\
\hline BHPS & . & & . & & 0.84 & 0.08 & $0.65 *$ & 0.12 & 0.88 & 0.16 \\
\hline \multicolumn{11}{|c|}{ Time-period (Ref. 1976-1979) } \\
\hline $1980-1983$ & & & & & & & $1.23 *$ & 0.09 & $1.22 *$ & 0.11 \\
\hline $1984-1987$ & & & & & & & $1.46 * *$ & 0.12 & $1.42 * *$ & 0.12 \\
\hline 1988-1991 & & & & & & & $1.77 * *$ & 0.14 & $1.91 * *$ & 0.15 \\
\hline 1980-1983*BHPS & & & & & & & 1.03 & 0.26 & 1.03 & 0.26 \\
\hline 1984-1987*BHPS & & & & & & & 0.86 & 0.22 & 0.75 & 0.20 \\
\hline 1988-1991*BHPS & & & & & & & 1.25 & 0.27 & 1.12 & 0.25 \\
\hline Controls & YES & & YES & & YES & & YES & & YES & \\
\hline Weights & YES & & YES & & YES & & YES & & YES & \\
\hline Sample 2008 & YES & & YES & & YES & & YES & & $\mathrm{NO}$ & \\
\hline Sample 1992 & NO & & NO & & NO & & NO & & YES & \\
\hline $\mathrm{N}$ & 1419 & & 4212 & & 5631 & & 5631 & & 7525 & \\
\hline
\end{tabular}

Note. Data referring to 1976-1991 from retrospective union histories. Only women's first unions $* * \mathrm{p}<.01 ; * \mathrm{p}<0.05$ 
trends in union stability, with decreasing stability across union cohorts. Model 3 pools data from both sources and documents that estimates of union dissolution are slightly lower in the BHPS. This difference is close to statistically significant. Model 4 splits observation time into four groups of years, and shows that for more distant periods the BHPS actually underreports union dissolution. This is a pattern opposite to what would be expected if surveys distant in time omit more events than surveys closer in time. How could this discrepancy be explained?

One possibility is that restricting the sample to those present in the 2008 wave of the BHPS introduces selective attrition as a problem. Model 5 therefore restricts the sample to individuals present in 1992. These estimates might be less comparable in terms of population covered, but are less likely to be affected by attrition. Indeed, when lifting this sample restriction more comparable estimates emerge across data sources.

\subsubsection{Attrition}

The previous results suggest that attrition might be an important problem. If the event of separation is connected to attrition, separation events will be recorded less often in longitudinal data. The BHPS employs various measures to stay in contact with respondents across time such as regular contact to increase commitment to the survey and the possibility to report household moves. Other measures include obtaining information on respondents who moved out from other household members. If whole households moved, neighbors, new residents, phone directories, shops, post offices, and contact persons provided by respondents in previous waves were consulted. ${ }^{1}$ Possibly due to these efforts, attrition rates are relatively low in the BHPS. Of the 6683 individuals in a union in Wave 15919 were interviewed in Wave 2 , an attrition rate of $11 \%$.

The BHPS declares all individual members of the households selected in Wave 1 to be "Original Sample Members". These members are followed across time individually, also if they move out of the original household. After separation, both original sample members are therefore followed to their new address/household. If after separation both partners drop out of the survey, there is normally no information available for them, which complicates performing an exhaustive test of how serious such attrition is for estimates of trends in union stability. However, we do have information on couples who separated and where at least one partner was interviewed again. This allows us to give some indication of whether the event of separation is related to attrition.

Of all couples present in the first wave, 128 couples ended up reporting a separation in Wave 2, but only 35 of these couples had both partners reporting the event in Wave 2 (not shown). In one case partners disagreed on whether they separated.

\footnotetext{
${ }^{1}$ See the BHPS User Manual Volume A; https://www.iser.essex.ac.uk/bhps/documentation/vola/ index.html
} 
But, in 92 cases only one of the two partners was interviewed again in Wave 2. The other partners had dropped out of the survey. This is $36 \%$ of the in total 256 persons involved. This is already a high percentage compared to the $11 \%$ among coupled individuals in general, but attrition is likely to look even more selective if persons are counted where both partners of the couple dropped out of the survey. This issue cannot be checked with the data at hand.

Both retrospective and prospective union information therefore will have to deal with non-response, and it is possible that survey data, regardless of the mode of collection, over-reports union stability. However, if estimates of union stability from prospective data come from several waves of data, attrition is likely to be a more serious issue for estimates based on longitudinal data.

\subsubsection{Comparing Retrospective and Prospective Reports of Trends in Union Stability}

The previous exercises have shown that attrition and the underreporting of dissolved unions in prospective data are issues that should be taken into account when estimating trends in union stability. How serious are these issues when ignored? To illustrate the consequences, I employ all data from the BHPS family histories, which is a combination of retrospective and prospective data, and pool it with the retrospective histories from Understanding Society.

Table 2.3 shows estimates of Cox proportional hazard models explaining union dissolution. Model 1 reveals that the BHPS reports higher union stability as compared to Understanding Society. The analysis presented so far suggested that especially prospective information might underestimate union stability. To check whether this is right, Model 2 splits the observation period into time before 1992 and time from 1992-2008 (i.e. this variable is time-varying). Pre-1992 information in the BHPS comes from retrospective data, whereas post-1992 information comes mainly from prospective data. The results show that it is the period covered by prospective data where union stability is higher in the BHPS. Model 3 shows how the same conclusion is reached when also excluding unions from both sources that lasted less than a year.

Prospective and retrospective data sources hence produce different estimates of union stability. Do they lead to different conclusions regarding trends in union stability? Figure 2.1 indicates the share of women's unions still intact after 7 years of duration depending on whether the BHPS or Understanding Society is used. For both data sources one can observe that the oldest union cohorts were the most likely to still be with their partner after 7 years. However, estimates from both sources would come to diverging conclusions regarding the stability of more recent union cohorts. Based on the BHPS data recent union cohorts appear to be more stable than unions formed between 1985 and 1994. The retrospective data from Understanding Society, however, indicates decreasing stability of unions across all cohorts with a 
Table 2.3 Pooled proportional hazard models explaining union dissolution of women's first unions

\begin{tabular}{|c|c|c|c|c|c|c|}
\hline & \multicolumn{6}{|c|}{ Pooled data } \\
\hline & Haz.R & SE & Haz.R & SE & Haz.R & SE \\
\hline & \multicolumn{2}{|l|}{ Model 1} & \multicolumn{2}{|c|}{ Model 2} & \multicolumn{2}{|c|}{ Model 3} \\
\hline \multicolumn{7}{|l|}{ Union cohort (Ref. 1975-79) } \\
\hline 1980-1984 & $1.27 * *$ & 0.07 & . & . & . & . \\
\hline 1985-1989 & $1.49 * *$ & 0.08 & . & . & . & . \\
\hline 1990-1994 & $1.59 * *$ & 0.09 & . & 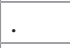 & . & . \\
\hline 1995-1999 & $1.75 * *$ & 0.10 & . & & . & . \\
\hline $2000-2004$ & $2.18 * *$ & 0.13 & . & . & . & . \\
\hline \multicolumn{7}{|l|}{ Dataset (Ref. Underst. Soc.) } \\
\hline BHPS & $0.89 *$ & 0.04 & 0.93 & 0.05 & 0.96 & 0.05 \\
\hline \multicolumn{7}{|l|}{ Time period } \\
\hline 1992-2008 (Ref. Pre-1992) & & & $2.48 * *$ & 0.07 & $2.15 * *$ & 0.06 \\
\hline 1992-2008*BHPS & & & $0.80 * *$ & 0.06 & $0.82 * *$ & 0.06 \\
\hline Controls & YES & & YES & & YES & \\
\hline Weights & YES & & YES & & YES & \\
\hline Sample BHPS from 2008 & YES & & YES & & YES & \\
\hline Prospective BHPS included & YES & & YES & & YES & \\
\hline Excluding spells $<1$ year & NO & & NO & & YES & \\
\hline $\mathrm{N}$ & 11,669 & & 11,669 & & 10,888 & \\
\hline
\end{tabular}

Controls: ethnicity, region, foreign born, education. $* * \mathrm{p}<.01 ; * \mathrm{p}<0.05$; Pooled data from BHPS and Understanding Society

Haz $R$ Hazard Ratio, SE Standard Error

possible stalling of that trend in the most recent cohort. Indeed, the break in the trend observed for the BHPS coincides with the switch from retrospective to prospective data in that data source. This is congruent with the suspicion that longitudinal prospective data might indeed overestimate union stability due to attrition and the underreporting of unions.

Models 1 and 2 of Table 2.4 reproduce the results in table form, and the subsequent models aim to make trends from both sources more comparable. Model 3 is based on a model where the sample of the BHPS is harmonized as much as possible to the Understanding Society sample: it only includes respondents interviewed in 2008 and controls for various background characteristics. Model 4 additionally includes sample weights provided by the BHPS to account for selective attrition across waves. In general, results do not become more similar across data sources. One exception is that after including sampling weights we now also observe decreased union stability among the youngest cohort in the BHPS, but the 1995-1999 union cohort remains oddly stable. It therefore has to be concluded that different data sources come to inconsistent conclusions regarding trends in union stability. I discuss what can still be said about trends in union stability in the final section of the chapter. 


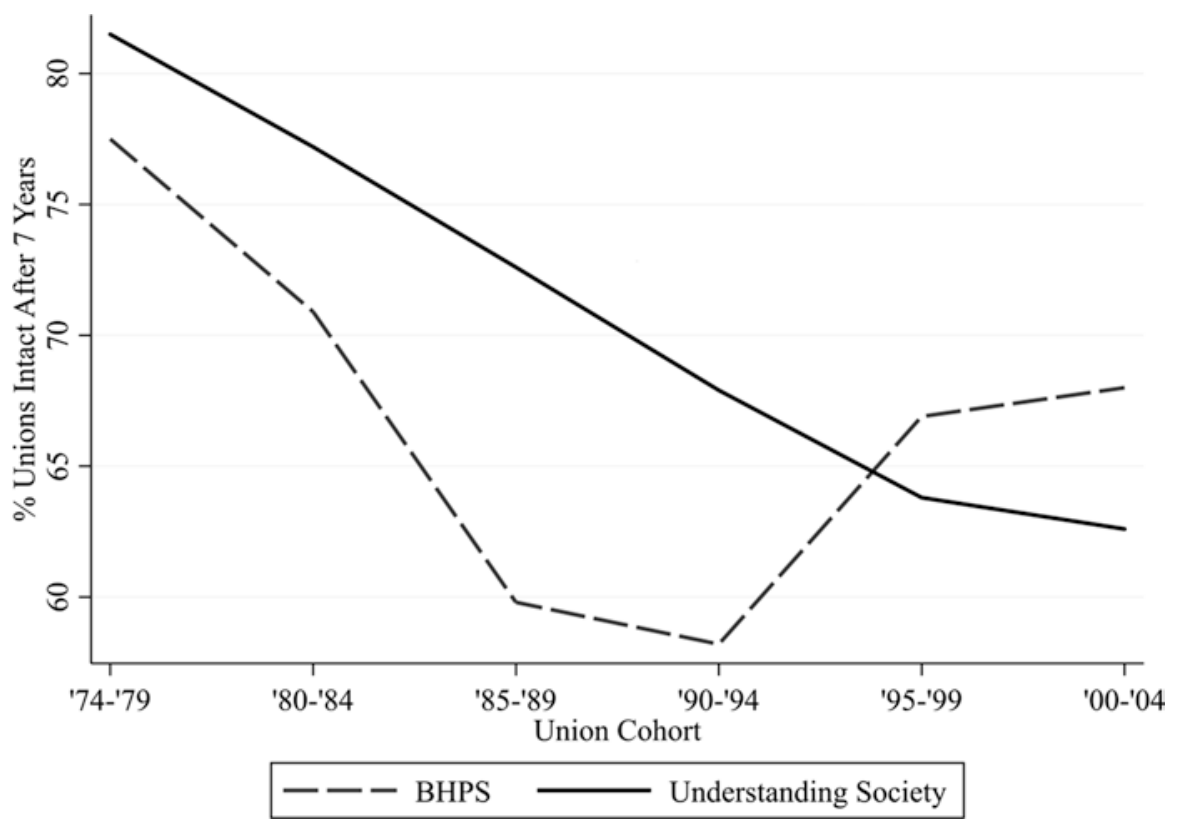

Fig. 2.1 Share of Women's First Unions Still Intact after 7 Years by Cohort and Dataset. Note. Data from British Household Panel Survey 1991-2008; N = 4026; Sample includes all respondents of BHPS and therewith differs from that of Table 2.3 for BHPS. Data from Understanding Society 2009 wave. $\mathrm{N}=8915$; Based on survival estimates using sts list in STATA. Weights included, but no controls

Table 2.4 Proportional hazard models explaining union dissolution of women's first unions

\begin{tabular}{|c|c|c|c|c|c|c|c|c|}
\hline & \multicolumn{2}{|c|}{$\begin{array}{l}\text { Understanding } \\
\text { society }\end{array}$} & \multicolumn{6}{|c|}{ British household panel survey } \\
\hline & Haz.R & SE & Haz.R & SE & Haz.R & SE & Haz.R & SE \\
\hline & \multicolumn{2}{|c|}{ Model 1} & \multicolumn{2}{|l|}{ Model 2} & \multicolumn{2}{|l|}{ Model 3} & \multicolumn{2}{|l|}{ Model 4} \\
\hline \multicolumn{9}{|c|}{ Union cohort (Ref. 1975-79) } \\
\hline $1980-1984$ & $1.36 * *$ & 0.08 & $1.23 *$ & 0.10 & 1.12 & 0.12 & 1.09 & 0.15 \\
\hline $1985-1989$ & $1.57 * *$ & 0.09 & $1.48 * *$ & 0.12 & $1.34 * *$ & 0.14 & $1.30 *$ & 0.17 \\
\hline 1990-1994 & $1.77 * *$ & 0.10 & $1.51 * *$ & 0.13 & $1.34 * *$ & 0.14 & 1.18 & 0.17 \\
\hline 1995-1999 & $2.04 * *$ & 0.12 & $1.23 *$ & 0.11 & 1.03 & 0.12 & 1.07 & 0.15 \\
\hline $2000-2004$ & $2.37 * *$ & 0.15 & $1.32 * *$ & 0.13 & $1.33 *$ & 0.17 & $1.68 * *$ & 0.27 \\
\hline Controls & YES & & $\mathrm{NO}$ & & YES & & YES & \\
\hline Attrition weights & N/A & & $\mathrm{NO}$ & & NO & & YES & \\
\hline Sample 2008 & N/A & & NO & & YES & & YES & \\
\hline $\mathrm{N}$ & 8915 & & 4026 & & 2131 & & 2753 & \\
\hline
\end{tabular}

Controls: ethnicity, region, foreign born, education. $* * \mathrm{p}<.01 ; * \mathrm{p}<0.05$. Understanding society numbers include sample weights to take oversampling of certain subgroups into account 


\subsection{Discussion}

Have unions become more or less stable over time in Britain? The answer appears to depend on the data source used. Prospective data indicates some signs of a reversal in the trend of increasing instability whereas retrospective data still paints a picture of ever less stable union cohorts. There are good reasons to doubt the validity of conclusions based on the prospective source of data: comparisons of retrospective and prospective data showed that a non-negligible number of dissolution events are "missing" from prospective reports and attrition appears directly related to separation events. Are there reasons to doubt the numbers based on retrospective union histories? Even though some events reported prospectively did not show up in retrospective information, these "missing" events were considerably smaller in number. Furthermore, different retrospective sources referring to the same target population delivered relatively consistent estimates of trends in union stability. If we take results based on retrospective data as the most likely to be valid, this would lead us to conclude that union stability has been increasing across cohorts, with a possible stall of that trend for the 2000-2004 union cohorts. There are a couple of qualifications to be made to that possible conclusion.

Firstly, even though the comparison of two retrospective histories presented in this chapter led to encouraging results, more research is needed to test to what extent retrospective unions provide biased information on trends in union stability. In particular, results on non-response raised concerns that surveys in general might under-report union dissolutions. Connecting survey estimates to administrative data might dramatically increase our understanding of how serious non-response is.

Secondly, the estimates presented in this chapter relied on a definition of unions that included co-residential unions and marriages only. On the one hand, the exclusion of LAT and non-residential relationships might have led to a picture of union stability that is not representative of all relationships that have an important impact on people's lives. On the other hand, the inclusion of all co-residential relationships might have given more importance to less committed relationships as compared to measures of marital stability. In this chapter, it was argued that co-residence is currently the best option available to filter committed from non-committed relationships, but applying other filters might lead to different estimates of union stability. A recommendation for future conceptual research is to work on measures of unions that might be better at such filtering. Conceptual and qualitative research also appears important to understand better how to prospectively measure cohabitation. In line with previous research (Manning and Smock 2005; Murphy 2000) I found that many cohabitations go unmeasured prospectively.

Finally, the most recent union cohort considered in this chapter already dates from 15 years ago at the time of writing. Crude divorce rates have dropped dramatically since 2006 in the United Kingdom: from 2.4 to 1.7 in 2015 (Eurostat ${ }^{2}$ ). There

\footnotetext{
${ }^{2}$ http://appsso.eurostat.ec.europa.eu/nui/show.do?dataset=demo_ndivind\&lang=en.

Accessed 29/05/2018.
} 
might therefore be exciting changes in levels of union stability occurring, but we currently do not have the data to document them. There are very few countries that have recent retrospective union history modules available to do so. Administrative data might form a solution in a select number of countries, but more research is needed to determine how reliable estimates of union stability are from such sources. The main recommendations for the future are therefore: (1) to further encourage the cross-verification of sources and determine how to best measure trends in union stability; and (2) to invest in the collection of data on union histories and connect them to administrative data. Research on trends in union stability might therewith one day become an as fruitful source for understanding changes in society as research on marital stability once was.

Acknowledgement I would like to thank Alina Pelikh, the reviewers and the editor for their useful comments on earlier drafts of this paper, as well as all the attendants at the various Divorce Conferences where parts of this work have been presented and developed.

This chapter benefited from the support of the Centre for Population, Family and Health $(\mathrm{CPFH})$ at the University of Antwerp and the Flemish Agency of Innovation and Entrepreneurship (Grant number: 140069), which enabled Open Access to this chapter.

The author acknowledges research funding from the Beatriu de Pinos program of the Generalitat de Catalunya (2016-BP-00121) as well as the EQUALIZE project led by Iñaki Permanyer (ERC2014-STG-grant agreement No 637768).

\section{References}

Aarskaug Wiik, K., Bernhardt, E., \& Noack, T. (2009). A study of commitment and relationship quality in Sweden and Norway. Journal of Marriage and Family, 71(3), 465-477.

Amato, P. R. (2010). Research on divorce: Continuing trends and new developments. Journal of Marriage and Family, 72(3), 650-666.

Becker, G. S., Landes, E. M., \& Michael, R. T. (1977). An economic analysis of marital instability. Journal of Political Economy, 85(6), 1141-1187.

Berrington, A., Beaujouan, E., Lyons-Amos, M., \& Ni Bhrolchain, M. (2011). Evaluation of the partnership histories in the Centre for Population Change GHS time series dataset (ESRC Centre for Population Change Working Paper, Number 12).

Brines, J. (1994). Economic dependency, gender, and the division of labor at home. American Journal of Sociology, 100(3), 652-688.

Brown, S. L., Stykes, J. B., \& Manning, W. D. (2016). Trends in Children's family instability, 1995-2010. Journal of Marriage and Family, 78(5), 1173-1183.

Cherlin, A. J. (2004). The deinstitutionalization of American marriage. Journal of Marriage and Family, 66(4), 848-861.

Cherlin, A. J. (2010). Demographic trends in the United States: A review of research in the 2000s. Journal of Marriage and Family, 72(3), 403-419.

Cohen, P. N. (2018). The coming divorce decline. https://doi.org/10.31235/osf.io/h2sk6.

Connidis, I. A., Borell, K., \& Karlsson, S. G. (2017). Ambivalence and living apart together in later life: A critical research proposal. Journal of Marriage and Family, 79(5), 1404-1418.

Esping-Andersen, G. (2016). Families in the 21st century. Stockholm: SNS Förlag.

Esping-Andersen, G., \& Billari, F. C. (2015). Re-theorizing family demographics. Population and Development Review, 41, 1), 1-1),31.

Esteve, A., García-Román, J., \& Lesthaeghe, R. (2012). The family context of cohabitation and single motherhood in Latin America. Population and Development Review, 38(4), 707-727. 
Goldscheider, F., Bernhardt, E., \& Lappegård, T. (2015). The gender revolution: A framework for understanding changing family and demographic behavior. Population and Development Review, 41(2), 207-239.

Hannemann, T., \& Kulu, H. (2015). Union formation and dissolution among immigrants and their descendants in the United Kingdom. Demographic Research, 33, 273-312.

Härkönen, J., Bernardi, F., \& Boertien, D. (2017). Family dynamics and child outcomes: An overview of research and open questions. European Journal of Population, 33(2), 163-184.

Hayford, S. R., \& Morgan, S. P. (2008). The quality of retrospective data on cohabitation. Demography, 45(1), 129-141.

Heuveline, P., \& Timberlake, J. M. (2004). The role of cohabitation in family formation: The United States in comparative perspective. Journal of Marriage and Family, 66(5), 1214-1230.

Hiekel, N., Liefbroer, A. C., \& Poortman, A. R. (2014). Understanding diversity in the meaning of cohabitation across Europe. European Journal of Population, 30(4), 391-410.

Jalovaara, M., \& Kulu, H. (2018). Separation risk over union duration: An immediate itch? European Sociological Review, 34(5), 486-500.

Kalmijn, M. (2012a). Longitudinal analyses of the effects of age, marriage, and parenthood on social contacts and support. Advances in Life Course Research, 17(4), 177-190.

Kalmijn, M. (2012b). Long-term effects of divorce on parent-child relationships: Within-family comparisons of fathers and mothers. European Sociological Review, 29(5), 888-898.

Kennedy, S., \& Ruggles, S. (2014). Breaking up is hard to count: The rise of divorce in the United States, 1980-2010. Demography, 51(2), 587-598.

Kiernan, K. (2004). Redrawing the boundaries of marriage. Journal of Marriage and Family, 66(4), 980-987.

Lesthaeghe, R. (1995). The second demographic transition in Western countries: An interpretation. Gender and family change in industrialized countries (pp. 17-62). Oxford: Oxford University Press

Lyngstad, T. H., Noack, T., \& Tufte, P. A. (2010). Pooling of economic resources: A comparison of Norwegian married and cohabiting couples. European Sociological Review, 27(5), 624-635.

Manning, W. D., \& Smock, P. J. (2005). Measuring and modeling cohabitation: New perspectives from qualitative data. Journal of Marriage and Family, 67, 989-1002.

McLanahan, S., \& Percheski, C. (2008). Family structure and the reproduction of inequalities. Annual Review of Sociology, 34, 257-276.

Mitchell, C. (2010). Are divorce studies trustworthy? The effects of survey nonresponse and response errors. Journal of Marriage and Family, 72(4), 893-905.

Murphy, M. (2000). The evolution of cohabitation in Britain 1960-95. Population Studies, 54, 43-56.

Musick, K., \& Michelmore, K. (2018). Cross-national comparisons of union stability in cohabiting and married families with children. Demography, 55, 1389-1421.

Oppenheimer, V. K. (1997). Women's employment and the gain to marriage: The specialization and trading model. Annual Review of Sociology, 23(1), 431-453.

Perelli-Harris, B., \& Gassen, N. S. (2012). How similar are cohabitation and marriage? Legal approaches to cohabitation across Western Europe. Population and Development Review, 38(3), 435-467.

Perelli-Harris, B., Kreyenfeld, M., Sigle-Rushton, W., Keizer, R., Lappegård, T., Jasilioniene, A., Berghammer, C., \& Di Giulio, P. (2012). Changes in union status during the transition to parenthood in eleven European countries, 1970s to early 2000s. Population Studies, 66(2), 167-182.

Pronzato, C. (2011). British Household Panel Survey Consolidated Marital, Cohabitation and Fertility Histories, 1991-2009. [data collection] (3rd ed.). University of Essex. Institute for Social and Economic Research, [original data producer]. UK Data Service. SN: 5629. https:// doi.org/10.5255/UKDA-SN-5629-1.

Raley, R. K., \& Wildsmith, E. (2004). Cohabitation and children's family instability. Journal of Marriage and Family, 66(1), 210-219. 
Stevenson, B., \& Wolfers, J. (2011). Trends in marital stability. In L. R. Cohen \& J. D. Wright (Eds.), Research handbook on the economics of family law (pp. 96-108). Cambridge, MA: National Bureau of Economic Research.

Strohm, C. Q., Seltzer, J. A., Cochran, S. D., \& Mays, V. M. (2009). "Living apart together" relationships in the United States. Demographic Research, 21, 177.

Teitler, J. O., Reichman, N. E., \& Koball, H. (2006). Contemporaneous versus retrospective reports of cohabitation in the Fragile Families Survey. Journal of Marriage and Family, 68, 469-477.

Thomson, E., \& Eriksson, H. (2013). Register-based estimates of parents' coresidence in Sweden, 1969-2007. Demographic Research, 29, 1153-1186.

U.S. Census Bureau. (2007). Number, timing, and duration of marriages and divorces: 2004 (Current Population Reports)

University of Essex. Institute for Social and Economic Research, Nat Cen Social Research, Kantar Public. (2018). Understanding Society: Waves 1-7, 2009-2016 and Harmonised BHPS: Waves 1-18, 1991-2009. [data collection] (10th ed.). UK Data Service. SN: 6614, https://doi. org/10.5255/UKDA-SN-6614-11

University of Essex. Institute for Social and Economic Research. (2010). British household panel survey: Waves 1-18, 1991-2009. [data collection] (7th ed.). UK Data Service. SN: 5151.

Wagner, M., Schmid, L., \& Weiß, B. (2015). Exploring increasing divorce rates in West Germany: Can we explain the Iron law of increasing marriage instability? European Sociological Review, 31(2), 211-229.

Young, A. F., Powers, J. R., \& Bell, S. L. (2006). Attrition in longitudinal studies: Who do you lose? Australian and New Zealand Journal of Public Health, 30(4), 353-361.

Open Access This chapter is licensed under the terms of the Creative Commons Attribution 4.0 International License (http://creativecommons.org/licenses/by/4.0/), which permits use, sharing, adaptation, distribution and reproduction in any medium or format, as long as you give appropriate credit to the original author(s) and the source, provide a link to the Creative Commons license and indicate if changes were made.

The images or other third party material in this chapter are included in the chapter's Creative Commons license, unless indicated otherwise in a credit line to the material. If material is not included in the chapter's Creative Commons license and your intended use is not permitted by statutory regulation or exceeds the permitted use, you will need to obtain permission directly from the copyright holder.

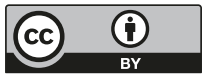

